Original Article

\title{
HPLC METHOD DEVELOPMENT AND VALIDATION FOR QUANTITATION OF TRIGONELLINE FROM MIRABILIS JALAPA LINN. LEAVES AND ENHANCEMENT IN EXTRACTION YIELD FROM ULTRA FINE POWDER
}

\author{
PADMA S. SATHE*, VIDYA V. DIGHE \\ Department of Chemistry, Ramnarain Ruia Colllege, Matunga (East), Mumbai 400019 \\ Email: padmasathe@gmail.com
}

Received: 24 Sep 2016, Revised and Accepted: 15 Nov 2016

\section{ABSTRACT}

Objective: Development and validation of a simple and reliable HPLC method for determination of an alkaloid, trigonelline, in the methanolic extract of Mirabilis jalapa Linn. leaves and comparing the extraction yields of trigonelline from micro powder and ultrafine powder.

Methods: The quantitation of trigonelline was carried out on a Phenomenex (Luna 5 U RP C 8 (2) column, $25 \mathrm{~cm} \mathrm{x} 4.6 \mathrm{~mm}$, i.d. $5 \mu \mathrm{m}$ ), using mobile phase comprising of distilled water containing $\mathrm{HCl}$ (pH adjusted to 3.5) and methanol in the volume ratio of 70:30, which was delivered at the flow rate of $0.5 \mathrm{ml}$ per min, at $35{ }^{\circ} \mathrm{C}$ column temperature. The detection and quantitation of trigonelline were carried out using PDA detector at the wavelength $\lambda=264 \mathrm{~nm}$.

Ultra-fine powder of Mirabilis jalapa Linn. was prepared using simple stepwise powdering method. The dried leaves of Mirabilis jalapa Linn. were ground using ice jacketed domestic mixer. This powder was sieved through a BSS 85 mesh sieve and considered as a micro powder. Further fine grinding was done by jet milling, followed by ball milling. This powder was considered as an ultra-fine powder.

Results: The proposed HPLC method for quantitation of trigonelline from dried leaf powder of Mirabilis jalapa Linn. is rapid, simple, accurate and precise.

Conclusion: The amount of trigonelline obtained using methanolic extracts of Mirabilis jalapa Linn. Ultra-fine powder and the micro powder was found to be $1.1103 \mathrm{mg} / \mathrm{g}$ and $0.7258 \mathrm{mg} / \mathrm{g}$ respectively.

Keywords: Mirabilis jalapa Linn., Nyctaginaceae, Trigonelline, HPLC, Ultra-fine powder

(C) 2016 The Authors. Published by Innovare Academic Sciences Pvt Ltd. This is an open access article under the CC BY license (http://creativecommons.org/licenses/by/4.0/) DOI: http://dx.doi.org/10.22159/ijcpr.2017v9i1.16611

\section{INTRODUCTION}

Mirabilis jalapa Linn., is a popular ornamental plant grown worldwide for the beauty of its flowers [1]. It is popularly known as four o'clock as the flowers open in the late afternoon or early evening.

Mirabilis jalapa Linn. from family Nyctaginaceae is known to possess various bioactivities, including antimicrobial, [2] antibacterial and antifungal, [3] antiviral and antiviroid, [4] antihelmintic, [5] antinociceptive, [6] anti-inflammatory, [7] wound healing, [8] hepato-protective, [9] hypoglycaemic [10] and hypolipidemic, [11] anti allergic and antiasthmatic [12].

It is also found to be effective in Glucolipid metabolization [13] and treatment of Prostatic Hyperplasia [14].

Trigonelline possesses both potential insulin sensitivity and shows hypoglycemic and hypolipidemic effects [15]. In Mirabilis jalapa Linn. plant, trigonelline was found in leaves, stem, flowers, roots and seeds [16]. Dried roots of Mirabilis jalapa Linn. Containing trigonelline, have been used as a traditional Chinese medicine [17].

HPLC, due to its sensitivity and accuracy, has been widely used as a quality control tool for the phytochemical evaluation of herbal drugs. Trigonelline is known to be an important bioactive alkaloid; hence the proposed HPLC method is developed to quantitate trigonelline present in the dried leaf powder of Mirabilis jalapa Linn. Further, the developed method is used for comparative quantitation of trigonelline present in the dried leaf micro powder and ultrafine powder of Mirabilis jalapa Linn.

Some high-performance liquid chromatography methods are reported in the literature for the quantitation of trigonelline from different plants.

HPLC methods are reported in literature for quantitation of trigonelline from dried leaf powders of 40 plant species including Mirabilis jalapa Linn., [16] from radix of Mirabilis jalapa Linn., [17] from herbal formulations containing Trigonella foenum-graecum (L.) seeds, [18] in Trigonella foenum-graecum [19] and in Trigonella foenum-graecum seeds [20].

In the present research work, a precise and accurate HPLC method has been developed and validated using International Conference on Harmonization (ICH) guidelines, which may be used as a fast and relatively cheaper method for quantitation of trigonelline from dried leaf powder of Mirabilis jalapa Linn. and further, it is used for comparative quantitation of trigonelline in micro and ultra-fine powders.

\section{MATERIALS AND METHODS}

Experimental reagents

All the solvents used in the analysis were of HPLC grade. Methanol (purity-99.7\%), and distilled water used were procured from LiChrosolv Merck, India. $\mathrm{HCl}$ pure $(35-38 \% \mathrm{w} / \mathrm{w})$ was procured from LOBA Chemie, Mumbai, India.

\section{Reference standard}

The reference standard trigonelline hydrochloride of Lot No. BCBH 2677V (mol. wt $173.6 \mathrm{~g} / \mathrm{mol}$ ) was purchased from Sigma-Aldrich Chemie GmbH (Aldrich Division, Steinbeim, Germany). It's reported purity is $98.3 \%$ in the Certificate of Analysis.

\section{Plant material}

Leaves of Mirabilis jalapa Linn. were collected from a domestic garden in Dombivli, Dist. Thane, Maharashtra, India. Its herbarium was prepared and authenticated from Botanical Survey of India, Pune, Maharashtra, India. (Certificate No. BSI/WC/Tech/2012/70) The duplicate herbarium was prepared and preserved in Ramnarain Ruia College. 
The collected leaves of Mirabilis jalapa Linn. were washed and dried in the shade. Initial grinding was done using a specially fabricated domestic mixer with an outer ice bath, and the ground leaf powder was sieved through BSS 85 mesh sieve. This was considered as a micro powder.

This powder was further ground to an ultra-fine size, by passing it thrice through a jet mill having a 4-inch chamber and two jets of air at a pressure of around $8 \mathrm{~kg}$ per $\mathrm{cm}^{2}$; particle size obtainable in this mill was up to one micron. The particle size was monitored using Malvern Mastersizer 2000 analyser.

About $400 \mathrm{~g}$ jet milled plant powder was ball milled. About $1600 \mathrm{gm}$ of $3.2 \mathrm{~mm}$ chrome balls were used. Milling was done at $980 \mathrm{rpm}$ for three cycles of forty-five minutes each. Liquid nitrogen was used for cooling. This powder was considered as an ultra-fine powder.

The particle size was monitored using Malvern Mastersizer 2000 analyser, and then using a Field Emission Scanning Electron Microscope.

Both micro powder and ultrafine powder were stored in airtight containers at room temperature $\left(28^{\circ} \mathrm{C} \pm 2{ }^{\circ} \mathrm{C}\right)$.

\section{Preparation of standard solution of trigonelline $(1000 \mu \mathrm{g} / \mathrm{ml})$}

Accurately weighed about $63.36 \mathrm{mg}$ of trigonelline hydrochloride equivalent to $50.0 \mathrm{mg}$ of trigonelline standard was transferred to a $50 \mathrm{ml}$ standard volumetric flask. It was dissolved in $20 \mathrm{ml}$ of methanol and the contents of the flask were sonicated in an ultrasonic bath (Model: TRANS-O-SONIC, Frequency: $50 \mathrm{~Hz}$ ) for 5 min for complete dissolution of trigonelline. The contents were then diluted up to the mark with methanol to obtain a stock solution of trigonelline with a concentration of $1000.0 \mu \mathrm{g} / \mathrm{ml}$.

\section{Preparation of mobile phase}

The mobile phase used in the present research work is water, in which $\mathrm{HCl}$ was added to adjust the $\mathrm{pH}$ to 3.5 and methanol in the volume ratio of 70.0: 30.0. Before use, the solvents were degassed in an ultrasonic bath. The flow rate was maintained constant at $0.5 \mathrm{ml} / \mathrm{min}$.

\section{Preparation of the sample solutions}

About $0.1 \mathrm{~g}$ micro powder of the leaves of Mirabilis jalapa Linn. was accurately weighed and transferred to $50.0 \mathrm{ml}$ stoppered conical flask. $10.0 \mathrm{ml}$ of methanol was added to it and the flask was sonicated in an ultrasonic bath (Model: TRANS-O-SONIC, Frequency: $50 \mathrm{~Hz}$ ) for $15 \mathrm{~min}$. Further, the sample solution was filtered through Whatman filter paper no.41. The filtrate was evaporated to dryness and then finally reconstituted in $10.0 \mathrm{ml}$ of methanol. The solution was then finally filtered using $0.45 \mu \mathrm{m}$ nylon filters (Millipore) before the analysis.

The exactly similar procedure was followed for preparing sample solution of ultra-fine powder of the leaves of Mirabilis jalapa Linn.

\section{Chromatographic conditions}

HPLC analysis was performed using Shimadzu UFLC Prominence Chromatograph, equipped with a binary gradient pump (LC-20AD), and fitted with autosampler (SIL-20 AC HT) and oven (CTO-20 AC).

A reversed phase, Phenomenex Luna 5 U RP C 8 (2) column (250 $\mathrm{mm} \times 4.6 \mathrm{~mm}, 5 \mu \mathrm{m}$ ) was used for the chromatographic separation. The oven temperature was $35^{\circ} \mathrm{C}$. The mobile phase used was water ( $\mathrm{pH}$ adjusted to 3.5 with $\mathrm{HCl})$ : methanol $(70.0: 30.0 \mathrm{v} / \mathrm{v})$. The flow rate of the mobile phase was $0.5 \mathrm{ml} / \mathrm{min}$. Injection volume was 10.0 $\mu \mathrm{l}$. The detection was done using PDA detector (SPD-M20A). The detection wavelength was $264 \mathrm{~nm}$. LC solution chromatographic software was used for data acquisition.

\section{Method validation}

\section{Linearity}

A series of standard solutions of trigonelline, in the concentration range of $0.01 \mu \mathrm{g} / \mathrm{ml}$ to $800.0 \mu \mathrm{g} / \mathrm{ml}$ were prepared and used for the determination of the linear dynamic range of trigonelline. $10.0 \mu \mathrm{l}$ of each of the standard solutions of trigonelline, in the concentration range of $0.01 \mu \mathrm{g} / \mathrm{ml}$ to $800.0 \mu \mathrm{g} / \mathrm{ml}$, were injected with Autosampler SIL-20 AC HT in the Phenomenex Luna 5 U RP C 8 (2) column (250 $\mathrm{mm} \times 4.6 \mathrm{~mm}, 5 \mu \mathrm{m}$ ), using mobile phase water (pH adjusted to 3.5 with $\mathrm{HCl})$ : methanol $(70.0: 30.0 \mathrm{v} / \mathrm{v})$ at the flow rate of $0.5 \mathrm{ml} / \mathrm{min}$. The chromatograms were recorded and peak areas for each injected concentration of trigonelline were noted. The response factor was calculated for each concentration of trigonelline, by dividing the peak area of trigonelline by corresponding concentration of trigonelline. It was observed that calculated response factor was constant in the range of $0.1 \mu \mathrm{g} / \mathrm{ml}$ to $100.0 \mu \mathrm{g} / \mathrm{ml}$.

$10.0 \mu \mathrm{l}$ of each of these standard solutions of trigonelline with a concentration of $0.1 \mu \mathrm{g} / \mathrm{ml}$ to $100.0 \mu \mathrm{g} / \mathrm{ml}$ were injected into the chromatographic system in triplicate, under the optimised chromatographic conditions. The peak areas were recorded for each injected concentration of trigonelline solution.

The peak areas were recorded and mean peak area, standard deviation (SD) and percent relative standard deviation (\% R. SD) for each concentration of trigonelline was calculated. The calibration curve of trigonelline was obtained by plotting a graph of mean peak area vs. applied concentration of trigonelline in the concentration range of $0.1 \mu \mathrm{g} / \mathrm{ml}$ to $100.0 \mu \mathrm{g} / \mathrm{ml}$ and it was found to be linear in this concentration range.

The regression analysis was carried out to calculate the calibration equation and correlation coefficient. The regression equation was $\mathrm{Y}=$ $44112 \mathrm{X}+2679$. (Correlation Coefficient $=0.999, \mathrm{n}=8$ ) The results listed in table 1.0, show that within the concentration range indicated, there was a good correlation between mean peak area and corresponding concentrations of the standard.

\section{Limit of detection (LOD) and limit of quantitation (LOQ)}

The limit of detection (LOD) and limit of quantitation (LOQ) was determined at a signal to noise ratio of 3:1 and 10:1 respectively. The LOD and LOQ values obtained are listed in table 1.

\section{Precision}

The method was validated in terms of instrumental precision, repeatability, and intermediate precision. Instrumental precision was studied by repetitive analysis $(n=10)$ of the standard solution of trigonelline, using the proposed HPLC method. $10.0 \mu \mathrm{l}$ of trigonelline solution having a concentration of $10.0 \mu \mathrm{g} / \mathrm{ml}$ was injected ten times in the chromatographic system, under optimised chromatographic conditions and the values of peak areas of trigonelline for each replicate analysis were recorded. As the value of $\%$ R. SD of the peak area of trigonelline for ten replicate injections was found to be less than 2, the instrumental precision was considered to be adequate for the analysis.

The repeatability was carried out in the same laboratory, on the same day, by analysing six sample solutions, each of dried leaf micro powder and ultrafine powder of leaves of Mirabilis jalapa Linn. Under the specified chromatographic conditions. The peak areas of trigonelline were recorded.

The values of mean peak area, standard deviation and percentage relative standard deviation were calculated for trigonelline. As the values of percentage relative standard deviation (\% R. SD) for the peak areas of trigonelline present in all the six samples of both micro and ultra-fine powders are below 2, it shows that the method is precise for performing the analysis.

The intermediate precision of the method was evaluated by analysing six sample solutions each of dried leaf micro powder and ultrafine powder of leaves of Mirabilis jalapa Linn. on three different days under the specified chromatographic conditions. The peak areas of trigonelline were recorded. The results were expressed as percentage relative standard deviation of the peak area of trigonelline and are listed in table 1.

The values of percentage relative standard deviation (\% R. SD) for the peak areas of trigonelline present in micro powder and ultrafine powder samples for six replicates for three successive days are below 2; hence the method is precise and reproducible for performing the analysis. 


\section{Stability of the standard solutions}

The stabilities of standard trigonelline solution were determined by comparing the peak area of a standard solution of trigonelline having a concentration of $10.0 \mu \mathrm{g} / \mathrm{ml}$ at different time intervals, for a period of minimum $48.0 \mathrm{~h}$, at room temperature. $10.0 \mu \mathrm{l}$ mixture of a standard solution of trigonelline was injected at intervals of $0,12,24$ and $48 \mathrm{~h}$ and analysed under the specified chromatographic conditions.

No significant degradation was observed within the given period, indicating that standard solution of trigonelline with a concentration of $10.0 \mu \mathrm{g} / \mathrm{ml}$ is stable for a period of minimum $48.0 \mathrm{~h}$ and is thus sufficiently stable for performing the analysis under normal laboratory conditions.

\section{System suitability}

System suitability was carried out to verify that resolution and reproducibility of the system were acceptable for the analysis. System suitability test was carried out by injecting $10.0 \mu \mathrm{l}$ of a standard solution of trigonelline, (concentration of $10.0 \mu \mathrm{g} / \mathrm{ml}$ ), into the column, in six replicates, under specified chromatographic conditions. The chromatograms were recorded. The values of percent relative standard deviation of peak area and retention time of standard were taken as an indicator of system suitability. The (\% R. SD) values for peak area and retention time for standard solution of trigonelline lie within the acceptable range; they were less than 2, indicating the suitability of the system.

Estimation of trigonelline in dried powder of leaves of Mirabilis jalapa Linn.

$10.0 \mu \mathrm{l}$ of each sample solution prepared by extracting about $0.1 \mathrm{~g}$ of dried leaf micro powder of Mirabilis jalapa Linn. with methanol as described earlier was injected into the column, under specified chromatographic conditions. The chromatograms were recorded. The values of peak areas and the mean of the peak area of trigonelline were recorded. Percent relative standard deviation of the peak area of trigonelline was determined. From the calibration curve, the amount of trigonelline present in the sample solution of Mirabilis jalapa Linn. was calculated. The exactly same procedure was followed for the ultra-fine powder.

The assay results are listed in table 1.

\section{Accuracy}

The accuracy of the method was established by carrying out recovery experiment to study if there was any interference of other constituents present in Mirabilis jalapa Linn. leaf powder on the peak of trigonelline.

About $0.1 \mathrm{~g}$ of dried leaf micro powder of Mirabilis jalapa Linn. was accurately weighed in four separate $50 \mathrm{ml}$ conical flasks. Known amounts of the standard trigonelline $(0.0 \mathrm{mg}, 0.1 \mathrm{mg}, 0.2 \mathrm{mg}$ and 0.3 $\mathrm{mg}$ ) respectively were added to each flask, $10.0 \mathrm{ml}$ of methanol were added, and extraction was carried out as described above. Each solution was analysed by the developed HPLC method, using the optimised chromatographic conditions, in seven replicates and the value of the amount of trigonelline recovered from the sample for each level was determined. The value of percent recovery was determined. The exactly same procedure was followed for the ultrafine powder. The results are listed in table 1.

The results indicate the good accuracy of the method for quantitative determination of trigonelline from the dried leaf powder of Mirabilis jalapa Linn.

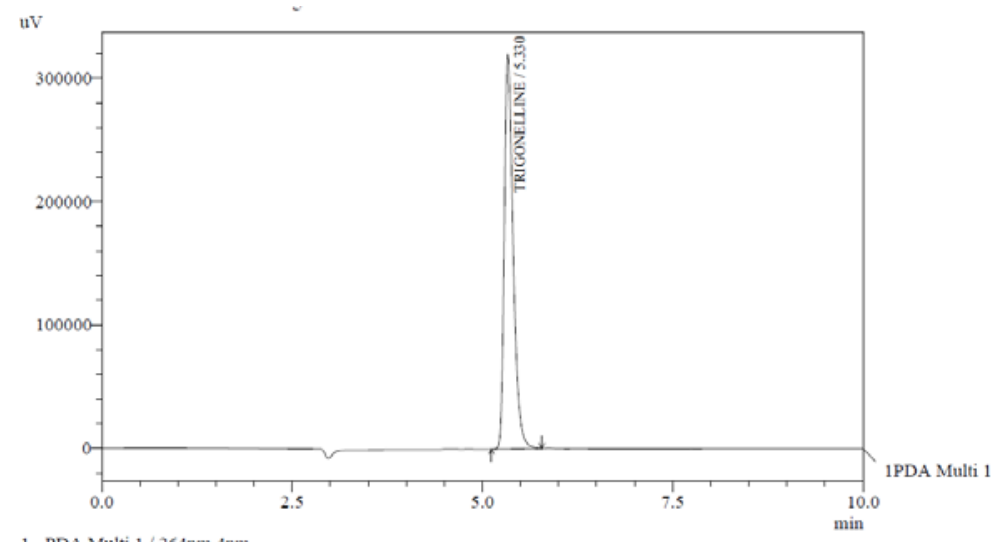

1 PDA Multi $1 / 264 \mathrm{~nm} 4 \mathrm{~nm}$

Fig. 1: Chromatogram for standard trigonelline

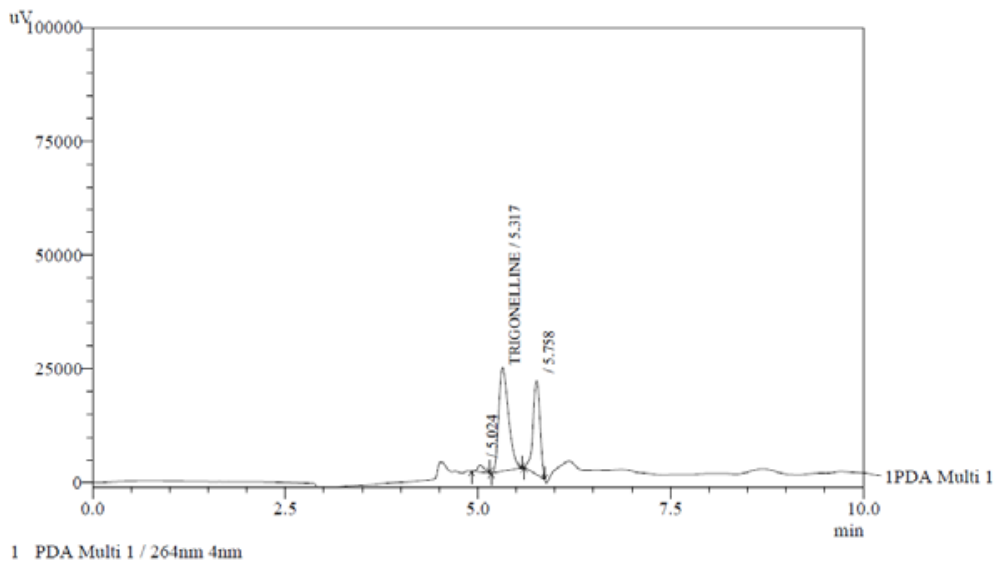

Fig. 2: Chromatogram for dried leaf micro powder of Mirabilis jalapa Linn 


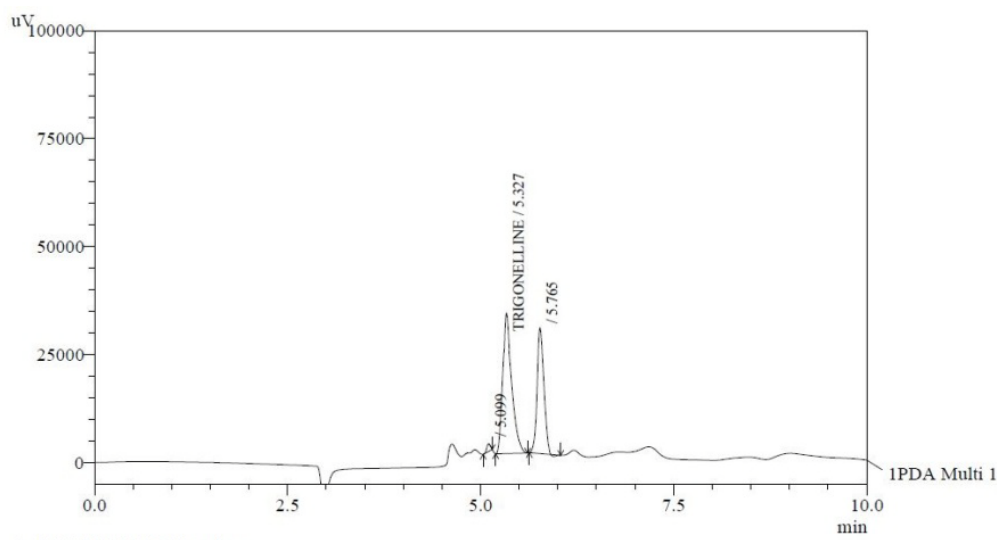

1. PDA Multi $1 / 264 \mathrm{~nm} 4 \mathrm{~nm}$

Fig. 3: Chromatogram for dried leaf ultra-fine powder of Mirabilis jalapa Linn

Table 1: Results of developed and validated HPLC method

\begin{tabular}{lc}
\hline Parameters & Results for trigonelline \\
\hline Linear range $(\mu \mathrm{g} / \mathrm{ml})$ & $0.1-100.0$ \\
Correlation coefficient & 0.999 \\
LOD $(\mu \mathrm{g} / \mathrm{ml})$ & 0.01 \\
LOQ $(\mu \mathrm{g} / \mathrm{ml})$ & 0.10 \\
System suitability (\%R. SD) & Less than 2 \\
Instrumental precision & Less than 2 \\
Stability of standard solution & Stable for minimum $48 \mathrm{~h}$ \\
& Micro powder \\
Repeatability (\% R. SD) (n=6) (On the same day) & 1.0653 \\
Intermediate precision (\% R. SD) (n=6) (For three successive days) & 0.9937 \\
Assay (mg/g) & 1.1220 \\
Percent Recovery & 0.7258 \\
\hline
\end{tabular}

\section{DISCUSSION}

Different mobile phases were tried for separation of trigonelline from other components of the dried leaf powder of Mirabilis jalapa Linn. and good separation was achieved by using water( $\mathrm{pH}$ adjusted to 3.5 with $\mathrm{HCl}$ ):methanol $70.0: 30.0$ as the mobile phase. Detection was carried out at $\lambda=264 \mathrm{~nm}$, as trigonelline showed a maximum response at this wavelength. The identity of the peak of trigonelline in the sample solutions was confirmed by comparing its retention time in the sample with that of the reference standard. The retention time for standard trigonelline was $5.330 \mathrm{~min}$.

Fig. 1 shows typical HPLC chromatogram of standard trigonelline, fig. 2 and fig. 3 show chromatograms for methanolic extract of dried leaf micro powder of Mirabilis jalapa Linn., the retention time for trigonelline was $5.317 \mathrm{~min}$, and ultra-fine powder of Mirabilis jalapa Linn., the retention time for trigonelline was 5.327 min respectively.

The developed method provided a good separation of the phytochemicals with the tailing factor 1.482 and resolution 2.054 for trigonelline peak in the micro powder sample and 1.515 and 2.042 respectively for trigonelline peak in the ultra-fine powder sample. These values lie within the acceptable limits.

HPLC method has been reported in the literature for quantitation of trigonelline from dried leaf powders of 40 plant species including Mirabilis jalapa Linn. Inertsil ODS-3 column was used (150 mm x 4.6 mm i.d., $5 \mu \mathrm{m}$ ); isocratic elution was carried out using $5 \%$ methanol solution including $0.1 \%$ phosphoric acid and $0.1 \%$ sodium 1 hexanesulphonate at a flow rate of $1 \mathrm{ml} / \mathrm{min}$. at $270 \mathrm{~nm}$. The retention time of trigonelline was $5.5 \mathrm{~min}$. [16] the $\mathrm{pH}$ of the mobile phase is 2.5 .

RP-HPLC determination of trigonelline from Radix of Mirabilis jalapa Linn. is reported. [17]Inertsil NH2 column is used, $(250 \mathrm{~mm} \times 4.6$ $\mathrm{mm}, 5 \mu \mathrm{m})$, the mobile phase was acetonitrile: water $80: 20 \mathrm{v} / \mathrm{v}$, the flow rate was $0.8 \mathrm{ml} / \mathrm{min}$. UV detection at $265 \mathrm{~nm}$.
RP-HPLC method for quantitation of trigonelline from herbal formulations containing Trigonella foenum-graecum (L.) seeds is reported. Cosmosil CN-MS column was used, eluted with methanol: distilled water [95:5, v/v; pH 3.5 using hydrochloric acid]. Detection was carried out at $\lambda=267 \mathrm{~nm}$ using a Photo Diode Array detector [18].

HPLC method for determination of trigonelline in Trigonella foenumgraecum is reported [19]. Asahipak NH2P-50 column was used and the mobile phase was acetonitrile-water in a ratio of 75:25. The detection was done at $\lambda=265 \mathrm{~nm}$.

HPLC method for determination of trigonelline in Trigonella foenumgraecum seeds is reported. Agilent Zorbax Eclipse XDB-C (18) column, mobile phase $0.37 \mathrm{mmol} / \mathrm{l}$ phosphoric acid ( $\mathrm{pH}=3.55)$, flow rate $1 \mathrm{ml} / \mathrm{min}$, and detection wavelength UV $265 \mathrm{~nm}$ [20].

The mobile phase selected for the present work is water $(\mathrm{pH}$ adjusted to 3.5 with $\mathrm{HCl}$ ): methanol 70.0:30.0 hence it is a mobile phase comprising of water in the greater proportion which makes it more environment-friendly and cost effective as compared to other reported mobile phases. The addition of hydrochloric acid to aqueous phase helped to improve the peak shape of trigonelline. In some reported methods, phosphoric acid and sodium 1-hexane sulphonate are used as components of mobile phase; these may prove hazardous for column life.

The selected mobile phase in the present work is simple and less acidic, which increases the durability of the column. A slower flow rate is used, thus the solvent consumption will be lesser.

As the values of percent relative standard deviation for instrumental precision, repeatability and intermediate precision are less than $2 \%$, a method is precise.

As the value of percent recovery for the standard is more than $98 \%$, indicating there is no interference from other constituents present in Mirabilis jalapa Linn. on the peak of trigonelline. 
Hence, a simple, cost-effective, precise and accurate HPLC method has been developed and validated using International Conference on Harmonization (ICH) guidelines, which may be used for quantitation of trigonelline from dried leaf powder of Mirabilis jalapa Linn.

Further, this method is used for quantitation of trigonelline from the micro powder and ultrafine powder of Mirabilis jalapa Linn. and the amount of trigonelline found in ultra-fine powder is more than that found in micro powder.

\section{CONCLUSION}

The developed HPLC method is precise, specific and accurate and can be used for the routine quality control analysis and quantitative determination of trigonelline from the dried leaf powder of Mirabilis jalapa Linn. Further, the amount of trigonelline found in ultra-fine powder is substantially more than that found in micro powder. This indicates that by grinding to a finer size, extraction of phytoconstituents is enhanced.

\section{CONFLICT OF INTERESTS}

Declare none

\section{REFERENCES}

1. Khare CP. Indian medicinal plants: an illustrated dictionary. $1^{\text {st }}$ Indian Reprint. Springer (India) Pvt. Ltd; 2007.

2. Dimayuga RE. Antimicrobial activity of medicinal plants from Baja California Sur/Mexico. Pharm Biol 1998;36:33-43.

3. Chakraborthy GS. Antibacterial and antifungal studies of Mirabilis jalap leaf extracts. J Pharm Sci Res 2009;1:79-82.

4. Vivanco JM, Querci M, Salazar LF. Antiviral and antiviroid activity of MAP-containing extracts from Mirabilis jalapa roots. Plant Disease 1999;83:1116-21.

5. Subin MZ, Aleykutty NA, Vidya V, Rachana VG. In vitro anthelmintic activity of aerial parts Mirabilis jalapa Linn. Int J Pharm Sci Rev Res 2012;12:107-10.

6. Walker CIB, Trevisan G, Rossato MF, Franciscato C, Pereira ME, Ferreira J, et al. the Antinociceptive activity of Mirabilis jalapa in mice. J Ethnopharmacol 2008;120:169-75.

7. Singh M, Kumar V, Singh I, Gauttam V, Kalia AN. Antiinflammatory activity of aqueous extract of Mirabilis jalapa Linn. leaves. Pharmacogn Res 2010;2:364-7.

8. Gogoi J, Nakhuru KS, Chattophadhayay P, Rai AK, Gogoi HK, Veer V. In vivo evaluation of cutaneous wound healing activity of Mirabilis jalapa $\mathrm{L}$ radix. Orient Pharm Exp Med 2014;14:103-9.
9. Basini J, Mohanalakshmi S, Anitha K. Protective effect of Mirabilis jalapa leaves on antitubercular drugs induced hepatotoxicity. Asian J Pharm Clin Res 2013;6:221-4

10. An-jun L, Yun-xia W, Hai-yan L, Tian-jiao MA, Guo-qiang Z. Hypoglycemic Effect of aqueous extract from Mirabilis jalapa on diabetic mice induced by administration of alloxan and glucose. Modern Food Sci Technol 2011;152:128-30.

11. Ji-Yin Z, Shi-Wen Z, Sheng-Ya Z, Jian-Yun Z, Ming-Jin J, Yan H. Hypoglycemic and Hypolipidemic effects of ethanolic extract of Mirabilis jalapa L. Root on normal and diabetic mice. J Evidence-Based Complementary Altern Med http://dx.doi.org/ 10.1155/2012/257374

12. Maxia A, Sanna C, Salve B, Kasture A, Kasture S. Inhibition of histamine-mediated responses by Mirabilis jalapa: confirming traditional claims made about antiallergic and antiasthmatic activity. Nat Prod Res 2010;24:1681-6.

13. Ming-jin J, Ji-yin Z, Sheng-ya Z, Xi-dong W, Zhi-xian M. Effects of ethanolic extract of Mirabilis jalapa roots on Glucolipid metabolization in diabetic rats. Chin J Exp Tradit Med Formulae 2013;7:285

14. Wang J, Cui X, Ke Y, Huang Q, Chen M, Xie J, Yao J. Effect of radix Mirabilis jalapae on experimental prostatic hyperplasia in mice. J Guangzhou Univ Tradit Chin Med 2005;5:393-5.

15. Mishkinsky J, Joseph B, Sulman FG. Hypoglycemic effect of trigonelline. Lancet 1967;2:1311-2.

16. Ashihara $\mathrm{H}$, Watanabe $\mathrm{S}$. Accumulation and function of trigonelline in non-leguminous plants. Nat Prod Commun 2014;9:795-8.

17. Song F, Zhang D, Zhong Y, Wang W, Zeng S. Content determination of trigonelline in Radix mirabilis by RP-HPLC. Tradit Chin Drug Res Clin Pharmacol 2005;3:189-90.

18. Sunita S, Menon S, Singh A, Mhatre M, Sayed N. A validated RP-HPLC method for quantitation of trigonelline from herbal formulations containing Trigonella foenum-graecum (L.) seeds. Pharm Methods 2011;2:157-60.

19. Zhao HQ, Qu Y, Wang XY, Zhang HJ, Li FM, Masao H. Determination of trigonelline in Trigonella foenum-graecum by HPLC. China J Chin Mater Med 2002;27:194-6.

20. Liu G, Shang M, Li H, Cai S. Determination of trigonelline in Trigonella foenum-graecum seeds. Drug Stand China 2005;4:194-6.

\section{How to cite this article}

- $\quad$ Padma S Sathe, Vidya V Dighe. HPLC METHOD development and validation for quantitation of trigonelline from Mirabilis jalapa Linn. leaves and enhancement in extraction yield from ultra-fine powder. Int J Curr Pharm Res 2017;9(1):62-66. 